\title{
Learning style of university students: Implications for improving entrepreneurial learning paradigm
}

\begin{abstract}
Learning is considered central in the process of entrepreneurial development. Learning styles play an important role in learning entrepreneurship at university. The main purpose of this study was to determine the university students' learning styles as a whole and in particular, the preferred learning styles of the students who had taken entrepreneurship related courses. A total of 1,554 university students from three research universities in Malaysia were selected as respondents of the study. The findings showed that university students preferred active, sensing, visual and sequential learning styles compared to reflective, intuitive, verbal, and global learning styles. The findings may guide policy makers, educators and lecturers at universities to understand how students learn and thus, provide facilities and instructional activities to foster entrepreneurial learning. This paper also presents suggestions towards improving entrepreneurial learning paradigm.
\end{abstract}

Keyword: Learning Style, Entrepreneurial Learning, and University Students 